\title{
In vitro effect of adenosine on the mRNA expression of Kir 2.1 and Kir 4.1 channels in rat retinal Müller cells at elevated hydrostatic pressure
}

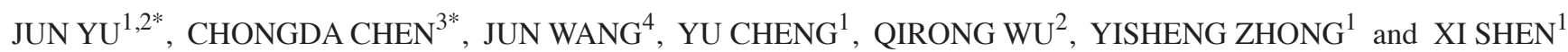 \\ ${ }^{1}$ Department of Ophthalmology, Ruijin Hospital, Shanghai Jiao Tong University School of Medicine, Shanghai 200025; \\ ${ }^{2}$ Department of Ophthalmology, Xinhua Hospital, Shanghai Jiao Tong University School of Medicine, Shanghai 200092; \\ ${ }^{3}$ Department of Ophthalmology, The Affiliated Cixi Hospital of Wenzhou Medical College, Cixi, Zhejiang 315300; \\ ${ }^{4}$ Institute of Traumatology and Orthopaedics, Ruijin Hospital, Shanghai Jiao Tong University School of Medicine,
} Shanghai 200025, P.R. China

Received October 23, 2011; Accepted January 11, 2012

DOI: $10.3892 /$ etm.2012.457

\begin{abstract}
The aim of this study was to investigate the expression of Kir 2.1 and Kir 4.1 channels at an elevated hydrostatic pressure in vitro, and to determine whether adenosine may modulate the mRNA expression of Kir 2.1 and Kir 4.1 channels in retinal Müller cells at an elevated hydrostatic pressure in vitro. Müller cells treated with $1 \mu \mathrm{M}$ adenosine at $40 \mathrm{mmHg} / 24 \mathrm{~h}$, and mRNA expression of Kir 2.1 and Kir 4.1 channels were examined using real-time PCR. Müller cells significantly increased the mRNA expression of Kir 2.1 and Kir 4.1 channels at $40 \mathrm{mmHg} / 24 \mathrm{~h}$. When further treated with $1 \mu \mathrm{M}$ adenosine at $40 \mathrm{mmHg} / 24 \mathrm{~h}$, the mRNA expression of the Kir 2.1 channels decreased, while the mRNA expression of the Kir 4.1 channels continued to increase. When the pressure was elevated, Müller cells were still able to take up $\mathrm{K}^{+}$and mediate the potassium concentration of the retina. Adenosine upregulated the expression of the Kir 4.1 channels, but weakly affected the expression of the Kir 2.1 channels.
\end{abstract}

\section{Introduction}

Glaucoma is a member of a group of eye diseases characterized by an increased intraocular pressure (IOP), degeneration

Correspondence to: Dr Xi Shen or Dr Yisheng Zhong, Department of Ophthalmology, Ruijin Hospital, Jiao Tong University School of Medicine, 197 Rui Jin Er Road, Shanghai 200025, P.R. China

E-mail: shenxi20111122@126.com

E-mail: zhongyisheng2011@126.com.cn

${ }^{*}$ Contributed equally

Key words: Müller cells, Kir 4.1 channels, Kir 2.1 channels, adenosine, pressure of the optic nerve and irreversible retinal ganglion cell (RGC) death (1). Elevated pressure is a significant risk factor $(2,3)$. Although the role of glial cells in glaucomatous retinae remains under debate, certain research has found that the expression of various genes by Müller cells can be altered in glaucomatous models, including the glial fibrillary acidic protein (GFAP), glutamine synthetase (GS) and nestin $(1,4-6)$. However, the situation in inwardly rectifying potassium (Kir) channels remains unclear.

Müller cells, the major glial cells of the retina, provide functional and structural support to the retinal neurons and constitute a functional link between neurons and vessels. One of the key roles of these cells is the spatial buffering of extracellular $\mathrm{K}^{+}$ ions. Müller cells transport $\mathrm{K}^{+}$through their cell bodies away from excited neurons, from extracellular regions of 'high $\mathrm{K}^{+1}$ to those of 'low $\mathrm{K}^{+1}$ in the retina. In Müller cells, the most significant mediators of $\mathrm{K}^{+}$buffering are the Kir channels, particularly the Kir 2.1 and Kir 4.1 channels (7-10). Kir 2.1 channels are strongly rectifying Kir channels, which allow inward $\mathrm{K}^{+}$currents even at high extracellular $\mathrm{K}^{+}$concentrations. However, Kir 4.1 channels are weakly rectifying Kir channels at negative potentials, allowing either 'inward' or 'outward' $\mathrm{K}^{+}$currents, depending on the concentration of extracellular $\mathrm{K}^{+}$. The present study suggests that the acceleration of $\mathrm{K}^{+}$clearance through the Kir 2.1 and Kir 4.1 channels in Müller cells can prevent the effects of neuronal information processing by depolarization caused by glia-derived $\mathrm{K}^{+}(8,11,12)$.

Adenosine is a natural chemical messenger, which binds to four subtypes $\left(\mathrm{A}_{1}, \mathrm{~A}_{2 \mathrm{~A}}, \mathrm{~A}_{2 \mathrm{~B}}\right.$ and $\left.\mathrm{A}_{3}\right)$ of adenosine receptors (ARs), and regulates the physiological functions of cells. In the retina, adenosine is capable of dilating vessels and serves an autoregulatory role in mediating the compensatory dilation in response to hypoxia, ischemia, hypoglycemia and high hydrostatic pressure (13-15).

The aim of this study was to investigate the expression of Kir 2.1 and Kir 4.1 channels at an elevated hydrostatic pressure in vitro, and determine whether adenosine can modulate the expression of Kir 2.1 and Kir 4.1 channels in retinal Müller cells at an elevated hydrostatic pressure in vitro. 


\section{Materials and methods}

Reagents. Adenosine was purchased from Sangon Biotech Co. Ltd. (Shanghai, China). A total of $1 \mu \mathrm{M}$ of adenosine was dissolved in serum-free medium prior to usage $(16,17)$.

Pressure system.T75 culture flasks, equipped with manometers, were placed in incubators and maintained at $37^{\circ} \mathrm{C}$, as the pressure mechanism, as described in detail in our previous study (3). A mixture of $95 \%$ air and $5 \% \mathrm{CO}_{2}$ was pumped into the flasks to obtain the pressure (2). To determine the short-term effects of elevated pressure on the Müller cells, we exposed our cultures to a wide range of pressures $(20,40,60$ and $80 \mathrm{mmHg}$ ). In our previous study, we evaluated the effects of glutamine synthetase (GS) at each pressure for 24 or $48 \mathrm{~h}$ and determined that a hydrostatic pressure of $40 \mathrm{mmHg} / 24 \mathrm{~h}$ produced the most reliable and measurable effects on the Müller cells. Thus, we used $40 \mathrm{mmHg} / 24 \mathrm{~h}$ as the experimental condition.

Cell separation and culture. Eyeballs from post-natal 0-3 day Sprague-Dawley rats (Slaccas Laboratory Animal Co. Ltd, Shanghai, China) were enucleated, and the retina of each was freely dissected and stored on ice in D-Hank's solution (Anresco). Tissue was dissociated by centrifugation and incubated for $15 \mathrm{~min}$ at $37^{\circ} \mathrm{C}$ in phosphate-buffered saline (PBS) containing $0.125 \%$ trypsin (Anresco). Finally, the cell suspension was cultured in $\mathrm{T} 75$ culture flasks at $37^{\circ} \mathrm{C}$ in humidified air containing $5 \% \mathrm{CO}_{2}$. Following primary initial outgrowth, the cell culture medium was replaced every $48 \mathrm{~h}$, and maintained in DMEM/F12 medium (Invitrogen, Carlsbad, CA, USA) supplemented with $100 \mathrm{U} / \mathrm{ml}$ penicillin, $100 \mu \mathrm{g} / \mathrm{ml}$ streptomycin and $10 \%$ fetal bovine serum (FBS) (Sijiqing).

Following 5-8 days, all of the flasks were agitated at $37^{\circ} \mathrm{C}$, $100 \mathrm{rpm}$ for $1 \mathrm{~h}$, and the cell culture medium was refreshed. Through agitation the other cell types (microglial cells and RGCs), which were initially adhered to the surface of the Müller cells, were rinsed off and a purified flat cell population was obtained. For passage, cell cultures were incubated at $37^{\circ} \mathrm{C}$ with PBS containing $0.125 \%$ trypsin.

Using immunocytochemisty, early passage Müller cells and the Müller cell marker, glutamine synthetase (GS), were characterized $(3,18)$. Contamination from other cell types was also tested and reported, and revealed $<10 \%$ of cells expressing specific makers for other cell types, including astrocytes and microglial cells.

Experiments were performed following the second passage when cell confluence was $80-90 \%$. Cells were cultured in serum-free medium for $16 \mathrm{~h}$. Then, the cells were cultured in $0 \mathrm{mmHg}$ (the control) or $40 \mathrm{mmHg}$ in the presence or absence of $1 \mu \mathrm{M}$ adenosine for $24 \mathrm{~h}$.

Immunofluorescence. The cultured cells which had grown to $80 \%$ confluence on the coverslips were fixed in sodium phosphate buffer $(100 \mathrm{mM}, \mathrm{pH} 7.4)$ containing $4 \%$ paraformaldehyde for $10 \mathrm{~min}$. The cells were washed in PBS, then incubated with various primary GS antibodies (Abcam, 1:5000, polyclonal rabbit anti-GS antibody) overnight at $4^{\circ} \mathrm{C}$. Subsequently, the cells were washed three times ( 5 min each) in PBS, and immunolabeled with fluorescein isothiocyanate Cy3 (BioLegend,1:200) linked with anti-mouse or anti-rabbit
IgG. The labeled cells were visualized and processed using an Axio microscope (Zeiss).

RNA extraction. Total RNA from cultures was isolated using TRIzol reagent (Gibco) according to the manufacturer's instructions. RNA was treated with RNase-free DNase (Sangon Biotech) to remove any genomic DNA contamination. The isolated RNA had an optical density (OD) 260/280 ratio of $\geq 2.0$.

Real-time PCR. To synthesize a cDNA template for PCR, we reverse-transcribed $2 \mu \mathrm{g}$ total RNA to a cDNA probe. The primer sequences were as follows: Kir 2.1 channels: sense, 5'-gcctcctggttgctgttc-3' and antisense, 5'-tggtggtctgcgtctcaat-3'; Kir 4.1 channels: sense, $5^{\prime}$-agttcgcacttcetatctaccg-3' and antisense, 5'-gggacgccactttcacaa-3'; $\beta$-actin: sense, 5'-cccatctat gagggttacgc-3' and antisense, 5'-tttaatgtcacgcacgatttc-3'. Real-time PCR was performed using a LightCycler instrument (Rotor-Gene), with a SYBR-Green PCR Master mix (Shuiyuan Biotech), according to the manufacturer's instructions. The PCR conditions were as follows: initial denaturation at $94^{\circ} \mathrm{C}$ for $5 \mathrm{~min}$ and 40 cycles performed at $94^{\circ} \mathrm{C}$ for $30 \mathrm{sec}, 55^{\circ} \mathrm{C}$ for $30 \mathrm{sec}$ and $72^{\circ} \mathrm{C}$ for $30 \mathrm{sec}$.

Statistical analysis. Data were reported as the means \pm standard error of the mean (each group, $n=3-4$ ). All analyses were performed with the SPSS statistical package. Data were analyzed using one-way analysis with a $\mathrm{P}<0.05$ used to indicate a statistically significant difference.

\section{Results}

Identification of cultured retinal Müller cells. We used immunofluorescence to identify the cultured Müller cells. The cultured cells demonstrated positive labeling for GS, the molecular markers for Müller cells in the retina. From the immunocytochemical labeling, the cultured cells were considered to be Müller cells (Figs. 1 and 2).

Effect of adenosine on the expression of Kir 2.1 channels in the cultured retinal Müller cells. In our study, the real-time PCR data revealed that the mRNA expression of Kir 2.1 channels was significantly increased in the Müller cells cultured in the presence or absence of $1 \mu \mathrm{M}$ adenosine at $40 \mathrm{mmHg}$ for $24 \mathrm{~h}$, compared with the normoxia control. However, there were no significant changes between the groups in which Müller cells were cultured in the presence or absence of $1 \mu \mathrm{M}$ adenosine at $40 \mathrm{mmHg}$ pressure for $24 \mathrm{~h}$; there was even a decline (Fig. 3).

Effect of adenosine on the expression of Kir 4.1 channels in the cultured retinal Müller cells. The real-time PCR data revealed that the mRNA expression of Kir 4.1 channels was significantly increased in the Müller cells cultured with $1 \mu \mathrm{M}$ adenosine at $40 \mathrm{mmHg}$ pressure for $24 \mathrm{~h}$, compared with the normoxia control or at $40 \mathrm{mmHg}$ pressure, in the absence of adenosine (Fig. 4).

\section{Discussion}

The results of this study demonstrated that in Müller cells, the mRNA expression of Kir 2.1 and Kir 4.1 channels significantly 


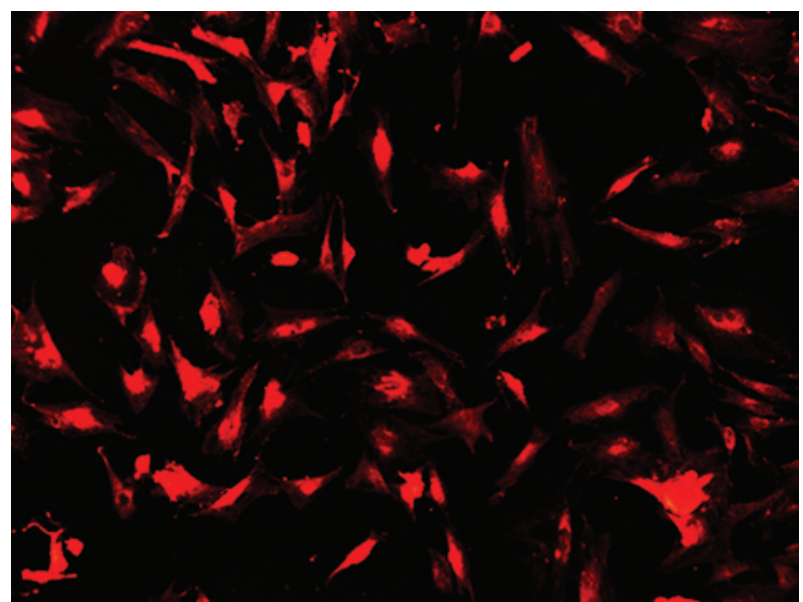

Figure 1. Identification of Müller cells. GS (red) was used to label the Müller cells. Magnification, x100. GS, glutamine synthetase.

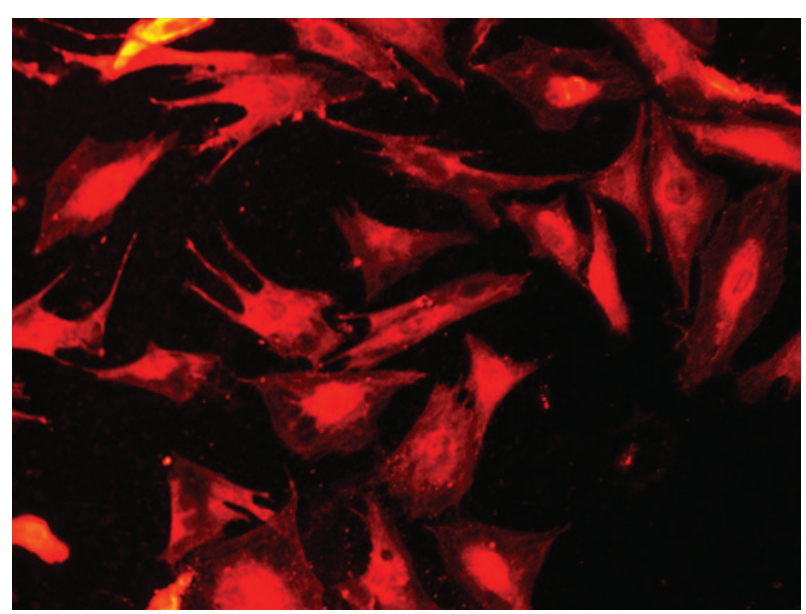

Figure 2. Identification of Müller cells. GS (red) was used to label the Müller cells. Magnification, x200. GS, glutamine synthetase.

increased at $40 \mathrm{mmHg}$ in vitro. Continually, when cells were further treated with $1 \mu \mathrm{M}$ adenosine at $40 \mathrm{mmHg}$ pressure, the mRNA expression of Kir 2.1 channels decreased; however, the mRNA expression of Kir 4.1 channels continued to increase, compared to when treated without adenosine at $40 \mathrm{mmHg}$ pressure (Figs. 3 and 4).

GS is predominantly expressed in the retina and has been used as a specific marker for Müller cells. In our study, more than $90 \%$ of cells in this culture system demonstrated positive markers for GS, therefore these cells were identified to be Müller cells.

The degeneration of RGCs in glaucoma is accompanied by morphological and functional changes in Müller cells, the main type of glial cell in the retina (18). Müller cells are responsible for the maintenance of homeostasis in the extracellular medium of the retina and protection of the neurons through the release of neurotrophins (19-22). Moreover, Müller cells can also have altered expression and functioning potassium channels, with consequential alteration in ion homeostasis and development of edema in the retina. Activated neurons release potassium ions. To avoid potassium-induced depolarization

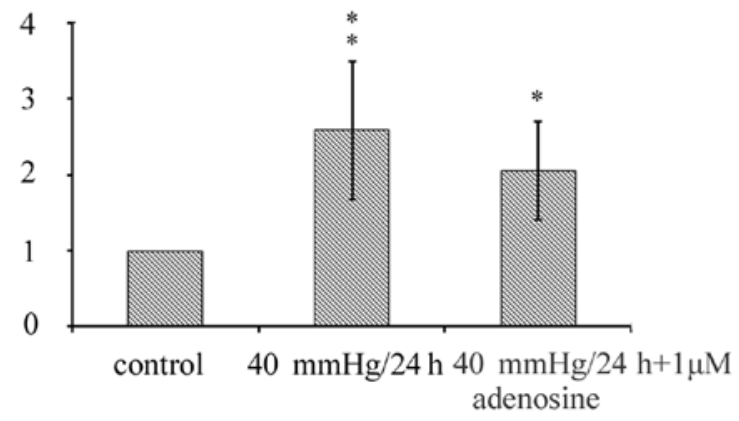

Figure 3. Kir 2.1 channel mRNA expression in Müller cells treated with adenosine. The mRNA expression of Kir 2.1 channels was significantly increased in Müller cells cultured in the presence or absence of $1 \mu \mathrm{M}$ adenosine at $40 \mathrm{mmHg}$ pressure for $24 \mathrm{~h}$, compared with the normoxia control. However, there were no significant changes between the groups in which Müller cells were cultured in the presence or absence of $1 \mu \mathrm{M}$ adenosine at $40 \mathrm{mmHg}$ pressure for $24 \mathrm{~h}$. ( $\mathrm{p}<<0.05,{ }^{* *} \mathrm{p}<0.01$, compared with the normoxia control).

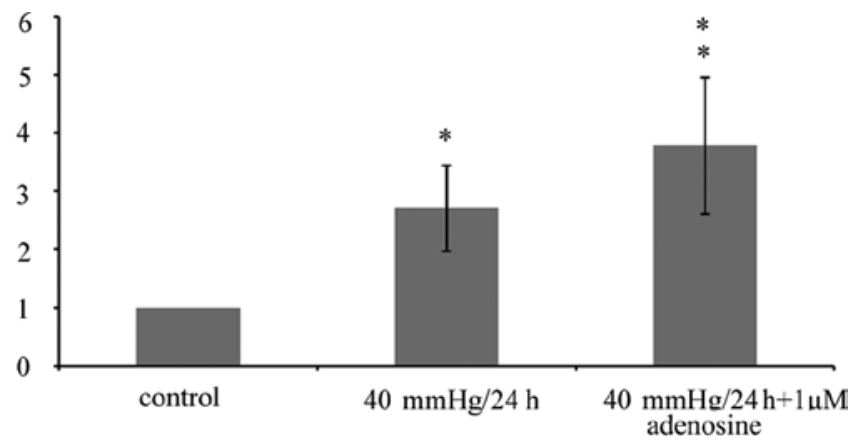

Figure 4. Kir 4.1 channel mRNA expression of Müller cells treated with adenosine. The mRNA expression of Kir 4.1 channels was significantly increased in the Müller cells cultured with $1 \mu \mathrm{M}$ adenosine at $40 \mathrm{mmHg}$ pressure for $24 \mathrm{~h}$, compared with the normoxia control or at $40 \mathrm{mmHg}$ pressure in the absence of adenosine. $\left({ }^{*} \mathrm{p}<0.05,{ }^{* *} \mathrm{p}<0.01\right.$, compared with the normoxia control).

of neurons, Müller cells take up excess potassium from the extracellular space, particularly in the plexiform layers of the retina, and release an appropriate amount of potassium into the spaces outside the retina. Kir channels localized in Müller cell membranes are used to mediate extracellular potassium. Müller cells express various types of potassium channels. Kir 2.1 channels are expressed in neuron-abutting membranes, through which Müller cells take up excess potassium. Kir 4.1 channels are expressed in membranes which are in close contact with spaces outside the neural retina. On the basis of the present results, we presumed that when the pressure elevated rapidly, Müller cells would remain capable of taking up $\mathrm{K}^{+}$, and mediate the potassium concentration of the retina.

Kir 2.1 channels are strongly rectifying Kir channels, which mediate only inward potassium currents into Müller cells, while Kir 4.1 channels are weakly rectifying Kir channels, which mediate bidirectional currents between the extraretinal tissues and the interior of the Müller cells $(23,24)$. Based on the present results it has been suggested that adenosine can upregulate the expression of Kir 4.1 channels, but weakly affect the expression of Kir 2.1 channels. The upregulation 
of Kir 4.1 channels should accelerate retinal $\mathrm{K}^{+}$clearance to prevent neuronal hyperexcitation and excessive release of glutamate.

There are still certain problems which require resolution, including whether adenosine is capable of affecting the expression of Kir 2.1 channels, and what would happen if the concentration of adenosine was changed. Moreover, the effect of adenosine on the protein expression of Kir 2.1 and Kir 4.1 channels require further study.

\section{Acknowledgements}

This study was supported by the National Natural Science Foundation of China (81170860), the Shanghai Municipal Education Committee Projects (10YZ38), the Shanghai Natural Science Foundation (11ZR1422000) and the Shanghai 'Science and Technology Innovation Action Plan' Basic Research Key Project (Nos. 11JC1407700 and 11JC1407701).

\section{References}

1. Bolz S, Schuteeauf F, Fires J, et al: $\mathrm{K}^{+}$currents fail to change in reactive retinal glial cells in a mouse model of glaucoma. Graefes Arch Clin Exp Ophthalmol 246: 1249-1254, 2008.

2. Sapptington R, Chan M and Calikns D: Interleukin-6 protects retinal ganglion cells from pressure-induced death. Invest Ophthalmol Vis Sci 47: 2932-2942, 2006.

3. Yu J, Zhong Y, Cheng Y, et al: The effect of high hydrostatic pressure on the expression of glutamine synthetase in rat retinal Müller cells cultured in vitro. Exp Ther Medicine 2: 513-516, 2011.

4. Wang X, Tay S, and Ng Y: An electron microscopic study of neuronal degeneration and glial cell reaction in the retina of glaucomatous rats. Histol Histopathol 17: 1043-1052, 2002.

5. Kanamori A, Nakamura M, Nakanishi Y, et al: Long-term glial reactivity in rat retinas ipsilateral and contralateral to experimental glaucoma. Exp Eye Res 81: 48-56, 2005.

6. Ishii M, Fujita A, Iwai K, et al: Differential expression and distribution of Kir 5.1 and Kir 4.1 inwardly rectifying $\mathrm{K}^{+}$channels in retina. Am J Physiol Cell Physiol 285: 260-267, 2003.

7. Kofuji P, Biedermann B, Siddharthan V, et al: Kir potassium channel subunit expression in retinal glial cells: implications for spatial potassium buffering. Glia 39: 292-303, 2002.

8. Bringmann A, Francke M, Pannicke T, et al: Role of glial $\mathrm{K}^{+}$ channels in ontogeny and gliosis: a hypothesis based upon studies on Müller cells. Glia 29: 35-44, 2000.
9. Chen K, and Nicholson C: Spatial buffering of potassium ions in brain extracellular space. Biophys J 78: 2776-2797, 2000.

10. Fakler B, Bond C, Adelman J, et al: Heterooligomeric assembly of inward-rectifier $\mathrm{K}^{+}$channels from subunits of different subfamilies: Kir2.1 (IRK1) and Kir4.1 (BIR10). Pflügers Arch 433: 77-83, 1996.

11. Yang D, Sun F, Thomas L, et al: Molecular cloning and expression of an inwardly rectifying $\mathrm{K}^{+}$channel from bovine corneal endothelial cells. Invest Ophthalmol Vis Sci 41: 2936-2944, 2000.

12. Shuck M, Piser T, Bock J, et al: Cloning and characterization of two $\mathrm{K}^{+}$inward rectifier (Kir) 1.1 potassium channel homologs from human kidney (Kir1.2 and Kir1.3). J Biol Chem 272: 586-593, 1997.

13. Hou X, Pal S, Choi W et al: Design and synthesis of truncated 4'-thioadenosine derivatives as potent and selective A3 adenosine receptor antagonists. Nucleic Acids Symp Ser 52: 641-642, 2008.

14. Daines B, Kent A, McAleer M, et al: Intraocular adenosine levels in normal and ocular-hypertensive patients. J Ocul Pharmacol Th 19: 113-119, 2003.

15. Wang Z, Che P, Du J, et al: Static magnetic field exposure reproduces cellular effects of the Parkinson's disease drug candidate ZM241385. PLoS One 5: 13883, 2010.

16. Shearer $\mathrm{T}$ and Crosson $\mathrm{C}$ : Adenosine A1 receptor modulation of MMP-2 secretion by trabecular meshwork cells. Invest Ophthalmol Vis Sci 43: 3016-3020, 2002.

17. CrossonC,Sloan C and Yates P: Modulation of conventional outflow facility by the adenosine A1 agonist N6-cyclohexyladenosine. Invest Ophthalmol Vis Sci 46: 3795-3799, 2005.

18. Tezel G and Wax MB: Hypoxia-inducible factor $1 \alpha$ in the glaucomatous retina and optic nerve head. Arch Ophthalmol 122: 1348-1356, 2004.

19. Fletcher E, Downie L, Ly A, et al: A review of the role of glial cells in understanding retinal disease. Clin Exp Optom 91: 67-77, 2008.

20. Kawasaki A, Otori Y and Barnstable C: Müller cell protection of rat retinal ganglion cells from glutamate and nitric oxide neurotoxicity. Invest Ophthalmol Vis Sci 41: 3444-3450, 2000.

21. Newman E and Reinchenbach A: The Müller cell: a functional element of the retina. Trends Neurosci 19: 307-312, 1996.

22. Vidal L, Díaz F, Villena A, et al: Reaction of Müller cells in an experimental rat model of increased intraocular pressure following timolol, latanoprost and brimonidine. Brain Res Bull 82: 18-24, 2010.

23. Reichenbach A, Wurm A, Pannicke T, et al: Müller cells as players in retinal degeneration and edema. Graefes Arch Clin Exp Ophthalmol 245: 627-636, 2007.

24. Nagelhus E, Horio Y, Inanobe A, et al: Immunogold evidence suggests that coupling of $\mathrm{K}^{+}$siphoning and water transport in rat retinal Müller cells is mediated by a coenrichment of Kir4.1 and AQP4 in specific membrane domains. Glia 26: 47-54, 1999. 